\title{
Creativity as a Resource of Adaptation in a Politically and Economically Unstable Environment
}

\author{
Yaroslava Z. Vasylkevych ${ }^{1}$, Olha M. Lomak ${ }^{1}$, Iryna M. Zozulia ${ }^{1}$, Diana V. Kochereva ${ }^{1}$ and \\ Oksana M. Kikinezhdi,"*
}

${ }^{1}$ Department of Psychology, The Socio-Historical Faculty, Hryhorii Skovoroda University in Pereiaslav, 30, Sukhomlynsky Str., Pereiaslav, 08401, Ukraine

${ }^{2}$ Department of the Psychology, Faculty of Pedagogy and Psychology, Ternopil Volodymyr Hnatiuk National Pedagogical University (TNPU), 2, Kryvonosa Str., Ternopil, 46027, Ukraine

\begin{abstract}
The purpose of the study was to identify the specifics of creativity in student age and the peculiarities of sociopsychological adaptation in a politically and economically unstable environment, as well as gender and micro group patterns of the relationship between creativity and adaptability. The methods such as the Guilford-Torrance method, "Desire for creativity" Scale, Kettell test, Methods of Moreno sociometry, Leary's method, and Dembo-Rubinstein method were used to monitor the variables. The study identified that non-verbal creativity develops in individuals aged 16-17 years. The creative attitude to life develops in the ones aged 17-18. At the age of 18-19, creativity becomes the most integrated into the system of personal characteristics are motivational and personal components of creativity, which form positive connections with the fundamental adaptive personality characteristics, which indicates a greater adaptive resource of creatively oriented individuals. It was also found that boys, compared to girls, were more prone to leadership, more persistent, assertive (E), more emotionally stable (C), calm (O), and also more independent (Q2). Girls were more likely to feel guilty, anxious (O), more sociable, open (A), sensitive, and vulnerable (I). The study found that students with a high level of development of divergent thinking and its components (cognitive factors of creativity) carry out interpersonal communication (as a component of adaptation) most flexibly and effectively making students less prone to depersonalisation and reducing the risk of emotional exhaustion and maladaptation.
\end{abstract}

Keywords: Creativity, adaptation resource, age, and gender features, environment.

\section{INTRODUCTION}

In modern conditions, the problem of creativity is one of the most studied in psychological science [1, 2]. However, in this area, there are still many unresolved issues, in particular, the problem of adaptability of the creative personality, the integrity of the manifestations of creativity, personal characteristics inherent in creative people [3,4]. Creativity is a universal activity necessary in the evolutionary perspective for adaptation and sustainability [5-7]. Creative abilities and the ability to adapt are formed throughout life, especially active during the student period, the time of the most intense changes, and the formation of personality.

To date, the problem of creativity has been considered mainly in the context of divergent thinking $[8,9]$. Although there are now trends in studying it as a holistic quality [10], covering various aspects [11], it should be noted that some aspects of creativity - it's verbal, nonverbal and motivational-personality components - are almost not studied.

\footnotetext{
*Address correspondence to this author at the Department of the Psychology, Faculty of Pedagogy and Psychology, Ternopil Volodymyr Hnatiuk National Pedagogical University (TNPU), 2, Kryvonosa Str., Ternopil, 46027, Ukraine; Tel: +38(098) 416-65-93; Fax: +38(0352)53-39-58;

E-mail: okkikinezhdi@gmail.com
}

Socio-psychological adaptation is one of the conditions for the development of individuality, but sometimes it is the bright individuality of a creative person that can prevent its adaptation in a politically and economically unstable environment [12]. Creativity can be both a cause and a consequence of problems in adaptation. Creative individuals can be rejected by a group of peers; creativity can be a source of problems in relationships with the environment $[13,14]$. On the other hand, creativity can promote adaptation (for example, if we talk about "retreat into creativity" as a way to restore the disturbed balance), seen as selfdevelopment, change of self and environment.

Socio-psychological adaptation in a politically and economically unstable environment is, in some way, correlated with various aspects of creativity [15]. The concept of creativity should be considered in two directions: creativity as a feature of thinking and creativity in the context of life, finding ways of development - as a creative attitude to life. Probably contradiction of the traits of a creative person, which is noted by many researchers is related to this [16-20].

The effectiveness of adaptation in a politically and economically unstable environment is associated with the use of constructive ways to overcome psychological barriers that promote new, non-standard solutions and the transition to a creative, innovative 
level of adaptation in the environment [21]. Psychological mechanisms for overcoming destructive tendencies of adaptation in a politically and economically unstable environment are: overcoming personal resistance to established stereotypes, which involves abandoning traditional behaviours [22]; development of alternative behaviours [23]; development of new patterns of activity and their integration into the formed personal and organisational structures [24].

Constructive overcoming barriers to adaptation in a politically and economically unstable environment requires the individual to show active, creative behaviour. This urges the need to explore the relationship between phenomena such as psychological barriers and creativity, which is a powerful resource for personal adaptation in a politically and economically unstable environment, that determines its willingness to change and abandon stereotypical behaviours and thinking.

Thus, this study is intended to identify the specifics of creativity in student age and the peculiarities of socio-psychological adaptation in a politically and economically unstable environment, as well as gender and micro group patterns of the relationship between creativity and adaptability.

\section{MATERIALS AND METHODS}

The study was prolonged and was conducted from September 2019 to March 2020. Its main objectives were: to determine the main aspects of creativity, as well as criteria and indicators of adaptation in a politically and economically unstable environment based on creativity; identifying the relationships between adaptation and creativity in groups with different structure of manifestation of creativity, as well as in gender and age groups.

\subsection{Sample}

The sample included 170 students of higher and professional education institutions in Pereiaslav-
Khmelnytskyi aged 16-19. Gender and age composition is presented in Table 1.

\subsection{Ethical Considerations}

Before the intervention, the routine approach based on the provision of written materials and an oral explanation was used to obtain the written informed consent from the sampled students to participate voluntarily in the experiment. The written consent to the research team for the use of the data resulted from the measurements was also obtained.

\subsection{Research Methods}

To study the creativity of students, techniques that determine the real and ideal degree of manifestation of creative qualities, the psychological profile of creativity, and the level of social creativity were used. GuilfordTorrance method was used to examine verbal creativity and nonverbal creativity with the domains such as "Verbal association", "Expression" (indicators: speed, flexibility, rarity), "Hidden form", along with the test of divergent thinking from The Williams scale (CAP) (indicators: speed, flexibility, rarity). Motivational and personal creativity was tested using Scale "Desire for creativity" from the questionnaire "Diagnosis of Personality Self-actualisation" (SAMOAL) by Kalina test of personal characteristics from The Williams scale (CAP) (indicators: curiosity, complexity, risk-taking, imagination). The socio-psychological adaptation was studied using Kettell test (factors O, C, Q4, Q4 /C), "Contact" and "Autosipathy" Scales from Kalina's questionnaire - for the domain of personal adaptation resource; Methods of Moreno sociometry (positive and negative choices in the areas of leisure and study) and Leary's method (self-assessment of interpersonal relationships (with teachers, friends, classmates)) for the domain of integration with the environment. the average performance score is drawn for the expert assessments of teachers (competence and confidence, constructive, creative approach, depth and cooperation, active position) was used to assess initial parameters of activity; and self-assessment (in terms of

Table 1: Gender and Age Composition of the Sample

\begin{tabular}{|c|c|c|c|c|c|}
\hline & Total & $\%$ & Boys & G & Girls \\
\hline \hline Total & 170 & 100 & 71 & 42 & 99 \\
\hline $16-17 y e a r s$ & 42 & 24 & 18 & 43 & 24 \\
\hline $17-18 y e a r s$ & 95 & 56 & 40 & 42 & 57 \\
\hline $18-19 y e a r s h$ methods & 33 & 19 & 13 & 39 & 58 \\
\hline
\end{tabular}


learning, ability, confidence, authority among peers) along with Dembo-Rubinstein method was applied for the domain of realisation of internal personality potential.

Statistica software was used for mathematical data processing to perform cluster, correlation, and factor analysis, to calculate descriptive statistics and Student's T-test.

Assumptions about the existence of individualtypological variants of creativity were tested using cluster analysis. This uses the Complete Linkage method, which allows selecting compact clusters consisting of the most similar elements. The clustering was based on 11 indicators of creativity. As a result, 4 groups were distinguished, which differ in the specifics of creativity.

A comparison of the obtained groups was performed using Student's t-test to compare the arithmetic means in the two samples and check the statistical significance of these differences. It allowed determining the significance of differences between clusters, as well as in gender and age groups by the parameters of creativity and the selected criteria of socio-psychological adaptation.

One-factor analysis of variance ANOVA was used to determine the effects of creativity and selected parameters of socio-psychological adaptation in gender, age, and cluster groups. Indicators of each of the scales of methods for assessing creativity were included in the analysis of variance separately as an independent (group) factor (qualitative variable) with three gradations of values: high, medium, and low levels.

Ex post facto, an experimental plan was used, in which participants were compared with different levels of creativity on individual indicators of adaptability and adaptation to the politically and economically unstable environment in general. Data were processed using a one-way analysis of variance (ANOVA) in the statistical software package SPSS, version 13.0.

\section{RESULTS}

The results of the study relied on measurements drawn for testing three age groups of students such as 42 individuals aged $16-17$ comprising 18 boys (43\%) and 24 girls (57), 95 individuals aged 17-18 (40 boys $(42 \%)$ and 55 girls $(58 \%))$ and 33 students aged $18-19$ (13 boys (39\%) and $20(61 \%)$ ).

The further presented results address the structure and specifics of the manifestation of creativity based on the analysis of level indicators of creativity in the general group, gender, and age subgroups (Tables 2 4).

Table 2: Mean Values of Cognitive Creativity in the Total Sample

\begin{tabular}{|c|c|c|}
\hline Variable & Boys & Girls \\
\hline \multicolumn{3}{|l|}{ Verbal creativity } \\
\hline speed & 5.3 & 7.6 \\
\hline flexibility & 8.3 & 7.7 \\
\hline originality & 7.3 & 8.6 \\
\hline Total score on verbal creativity & 20.9 & 8.0 \\
\hline \multicolumn{3}{|l|}{ Nonverbal creativity } \\
\hline speed & 12.4 & 10.1 \\
\hline flexibility & 5.6 & 10.4 \\
\hline originality & 8.9 & 11.8 \\
\hline Total score on verbal creativity & 26.9 & 10.8 \\
\hline
\end{tabular}

The analysis shows an increase in all indicators of creativity, except for nonverbal creativity, which growth is observed only in the period from $16-17$ to $17-18$ years because during this period there is a leap in the

Table 3: Mean Values of Motivational and Personality Creative Characteristics in the Total Sample

\begin{tabular}{|c|c|c|c|c|}
\hline Variable & Boys & Norms & Maximum for the scale & Girls \\
\hline Curiosity & 15.3 & 17.8 & 24 & 7.7 \\
\hline Imagination & 13.4 & 15.6 & 24 & 8.2 \\
\hline Risk-taking & 17.2 & 17.0 & 26 & 7.5 \\
\hline Complexity & 14.1 & 17.2 & 24 & 7.9 \\
\hline General score on motivational and personal creativity & 60.0 & 67.6 & 100 & 7.8 \\
\hline Desire for creativity & 9.2 & 15 & 15 & 7.4 \\
\hline
\end{tabular}


Table 4: Mean Values of Creative Characteristics in Samples by Gender and Age

\begin{tabular}{|c|c|c|c|c|c|}
\hline Variable & $\mathrm{X} 1$ & $\mathrm{X} 2$ & Tcr. & D1 & D2 \\
\hline Boys and girls & boys & girls & & & \\
\hline verbal speed & 4.3 & 5.1 & $-2.7^{*}$ & 1.8 & 1.8 \\
\hline verbal flexibility & 7.2 & 8.3 & $-2.6^{*}$ & 2.8 & 2.8 \\
\hline verbal originality & 5.7 & 7.6 & $-2.7^{*}$ & 4.7 & 4.6 \\
\hline $16-17$ and $17-18$ years & 16-17 years & 17-18 years & & & \\
\hline curiosity & 16 & 14 & $2.7^{*}$ & 4.5 & 3.7 \\
\hline nonverbal speed & 11 & 12.5 & $-2.9^{*}$ & 2.4 & 2.9 \\
\hline nonverbal flexibility & 4.7 & 5.3 & $-4.6^{*}$ & 0.9 & 0.7 \\
\hline nonverbal originality & 7 & 9.6 & $-2.4^{*}$ & 6.0 & 6.0 \\
\hline verbal speed & 3.8 & 4.9 & $-3.3^{*}$ & 1.8 & 1.6 \\
\hline verbal flexibility & 6.6 & 8.1 & $-2.9^{*}$ & 3.0 & 2.7 \\
\hline verbal originality & 4.3 & 7.2 & $-3.7^{*}$ & 3.9 & 4.4 \\
\hline $17-18$ and $18-19 y e a r s$ & 17-18 years & 18-19 years & & & \\
\hline The desire for creativity & 9.0 & 8.0 & $2.3^{*}$ & 2.0 & 2.4 \\
\hline nonverbal originality & 9.6 & 6.6 & $2.4^{*}$ & 6 & 6.6 \\
\hline 16-17and 18-19years & 16-17years & 18-19 years & & & \\
\hline nonverbal flexibility & 4.7 & 5.4 & $-2.9^{*}$ & 0.9 & 1.2 \\
\hline verbal speed & 3.8 & 5.5 & $-3.9^{*}$ & 1.8 & 1.9 \\
\hline verbal flexibility & 6.6 & 8.5 & $-2.7^{*}$ & 3.0 & 2.9 \\
\hline verbal originality & 4.3 & 8.8 & $-4.2^{*}$ & 3.9 & 5.5 \\
\hline
\end{tabular}

development of creativity, which goes from imitation to independence. The decline in creative attitudes to life can be explained by the development of certain stereotypes of behaviour. The maximum differences in all types of creativity are observed between 16-17year-olds and 17-18-year-olds, which is due to the peculiarities of this age period (17-18 years), which is characterised by maximum mobility of development, active restructuring of personality structure.

A cluster analysis was performed to identify the specifics of the manifestation of creativity for all three groups of indicators of creativity. The clustering is based on the most informative verbal and nonverbal indicators (speed, flexibility, and originality), as well as motivational and personality characteristics inherent in a creative individual (curiosity, imagination, complexity, risk-taking, desire for creativity). As a result of clustering, the sample was divided into four typological subgroups (Table 5), which differ in the level and nature of creativity as a resource for adaptation in a politically and economically unstable environment.

Based on the analysis of Table 6, it was found that the verbal and nonverbal creativity parameters were distributed as follows: the first group - cognitively

Table 5: Mean Values of the Characteristics of Cognitive Creativity in Cluster Groups

\begin{tabular}{|c|c|c|c|c|}
\hline Cluster groups & $1^{\text {st }}$ cluster & $2^{\text {nd }}$ cluster & $3^{\text {rd }}$ cluster & $4^{\text {th }}$ cluster \\
\hline Nonverbal speed & 10.75 & 11.5 & 10.7 & 16.1 \\
\hline Nonverbal flexibility & 4.95 & 5.1 & 5.1 & 5.8 \\
\hline Non-verbal originality & 5.85 & 7.2 & 5.9 & 18.4 \\
\hline Total indicator of nonverbal creativity & 21.6 & 23.8 & 21.7 & 40.3 \\
\hline Verbal speed & 3.8 & 6.9 & 4.2 & 5.6 \\
\hline Verbal flexibility & 7.05 & 10.9 & 6.9 & 8.1 \\
\hline Verbal originality & 4.15 & 13.7 & 4.9 & 7.8 \\
\hline Total indicator of verbal creativity & 15 & 31.5 & 16 & 21.5 \\
\hline
\end{tabular}


Table 6: Mean Values of Motivational and Personality Characteristics in Cluster Groups

\begin{tabular}{|c|c|c|c|c|}
\hline Cluster groups & Uncreative & Verbally creative & Cognitively uncreative & $\begin{array}{c}\text { Nonverbally } \\
\text { creative }\end{array}$ \\
\hline \hline Curiosity & 13.7 & 16.1 & 17.0 & 15.6 \\
\hline Imagination & 11.2 & 13.8 & 15.6 & 13.8 \\
\hline Risk-taking & 15.6 & 17.8 & 18.5 & 17.7 \\
\hline Complexity & 11.4 & 14.5 & 16.5 & 14.9 \\
\hline Total figure & 55.9 & 62.3 & 67.6 & 8.8 \\
\hline Desire for creativity & 8.4 & 8.5 & 8.6 \\
\hline
\end{tabular}

uncreative ("uncreative"); the second group - creative verbally and medium creative nonverbally ("verbally creative"); the third group - cognitively uncreative (let us call it also "uncreative"); and the fourth - creative nonverbally, medium creative verbally ("nonverbally creative").

As for the motivational and personality characteristics inherent in the creative individual, the pattern by clusters is as follows (Table 6 ).

Given that the number of girls in the sample slightly exceeded the number of boys (99 and 71, respectively, which was $59 \%$ and $41 \%$ ), the gender composition of the second, third, and fourth clusters can be considered as approximately proportional to the total sample, while there were slightly more young men in the first, uncreative cluster (the numerical and genderage composition of the subjects of all clusters are presented in Table 7).

Thus, based on the results obtained in the cluster analysis, it was concluded that high performance in one area of manifestation of creativity could be combined with moderate or low performance in another. That is, there are three independent substructures of creativity (verbal, nonverbal, and motivational-personality) almost unrelated to each other in the structure of creative characteristics.

Table 7: Numerical and Gender-Age Composition of Cluster Groups

\begin{tabular}{|c|c|c|c|c|c|c|c|c|c|c|}
\hline & Total & $\%$ & $1^{\text {st }}$ cluster & $\%$ & $2^{\text {nd }}$ cluster & $\%$ & $3^{\text {rd }}$ cluster & $\%$ & $4^{\text {th }}$ cluster & $\%$ \\
\hline Total number & 170 & 100 & 71 & 42 & 26 & 15 & 40 & 24 & 30 & 18 \\
\hline Boys & 71 & 42 & 35 & 49 & 9 & 13 & 14 & 8 & 12 & 17 \\
\hline Girls & 99 & 58 & 36 & 36 & 17 & 17 & 26 & 26 & 18 & 18 \\
\hline $16-17$ years & 42 & 24 & 21 & 50 & 4 & 10 & 13 & 31 & 4 & 10 \\
\hline $17-18$ years & 95 & 56 & 37 & 39 & 12 & 13 & 21 & 22 & 25 & 26 \\
\hline
\end{tabular}

Table 8: Differences in the Mean Values of Personality Traits in the Samples by Gender

\begin{tabular}{|c|c|c|c|c|c|}
\hline Variable & $\mathrm{X} 1$ & $X 2$ & $T$ & D1 & D2 \\
\hline Boys/girls & Boys & Girls & & & \\
\hline $\mathrm{O}$ & 8.1 & 9.2 & -2.5 & 3.0 & 3.0 \\
\hline$A$ & 10.0 & 12.3 & -4.8 & 3.3 & 3.3 \\
\hline$E$ & 11.2 & 9.0 & 5.0 & 2.8 & 3.1 \\
\hline 1 & 7.5 & 11.5 & -8.7 & 2.9 & 3.1 \\
\hline Q2 & 10.2 & 8.8 & 2.9 & 3.4 & 3.2 \\
\hline$C$ & 10.9 & 9.2 & 3.3 & 3.2 & 3.4 \\
\hline Q4/C & 1 & 1.4 & -2.3 & 0.8 & 0.9 \\
\hline
\end{tabular}


Table 9: Differences in the Mean Values of Styles of Interaction with the Environment in Cluster Subgroups

\begin{tabular}{|c|c|c|c|c|}
\hline & Uncreative & Verb. Creat. & Pers. Creat. & Non-verb. Creat. \\
\hline \hline Authoritarian & 8.0 & 9.2 & 9.1 & 10.3 (from $1 \mathrm{cl}$.) \\
\hline Friendly & 7.0 (from 3 cl.) & 8.0 & 8.6 & 8.1 \\
\hline Altruistic & 7.0 (from 2,3,4 cl.) & 8.7 & 8.7 & 8.8 \\
\hline Dominance index & 3.5 & 6.3 & 5.9 & 7.5 (from $1 \mathrm{cl}$.) \\
\hline
\end{tabular}

The specifics of creativity and personality adaptive resources are presented in Table $\mathbf{8}$.

As Table 8 shows, the following differences are found in the comparison of samples by gender and age: boys, compared to girls, are more prone to leadership, more persistent, assertive $(E)$, more emotionally stable (C), calm (O), and also more independent (Q2). Girls are more likely to feel guilty, anxious (O), more sociable, open (A), sensitive, and vulnerable (I). Girls also have more correlated frustration tension, i.e. they feel more tension with less emotional stability. No significant age differences were obtained.

Thus, verbally creative individuals differ significantly from non-creative ones in less frustration and tension. Boys, compared to girls, are more prone to leadership, more persistent, assertive, more emotionally stable, calmer, and more independent. Girls are more likely to feel guilty, anxious, more sociable, open, sensitive, and vulnerable.

Next, the mean values of indicators of integration of an individual with the environment in the subgroups were analysed (Table 9).

As we can see from Table 9, the non-verbalcreative group is in first place in terms of the dominance index, which also distinguishes in the trend and all creative groups compared to non-creative from others in terms of authoritarianism and dominance. Non-verbal-creative individuals, in contrast to uncreative, are more likely to show self-orientation, propensity for rivalry, dominance, straightforwardness, and harshness in the assessment of other people. The

Table 10: The Influence of the Effects of Creativity on the Adaptation of an Individual in a Politically and Economically Unstable Environment

\begin{tabular}{|c|c|}
\hline $\begin{array}{c}\text { Components of adaptation in a politically and economically } \\
\text { unstable environment }\end{array}$ & $\begin{array}{l}\text { Factors of creativity that reduce the risk of maladaptation } \\
\text { and its components }\end{array}$ \\
\hline Personality & $\begin{array}{l}\text { 1. Divergent thinking: } \\
(F(2.57)=4.711 ; p=0.013) \\
\text { 2. Level of development of thinking: } \\
(F(2.57)=3.454 ; p=0.038)\end{array}$ \\
\hline Interpersonal communication & $\begin{array}{c}\text { Divergent thinking: } \\
(\mathrm{F}(2.57)=4.231 ; \mathrm{p}=0.019)\end{array}$ \\
\hline Activity & $\begin{array}{l}\text { 1. Overall creative potential: } \\
(F(2.57)=3.135 ; p=0.05) \text {. } \\
\text { 2. Creativity of an individual: } \\
(F(2.57)=4.608 ; p=0.014) \text {. } \\
\text { 3. Creativity in solving problems: } \\
(F(2.57)=3.855 ; p=0.027)\end{array}$ \\
\hline Level (phase) of adaptation & $\begin{array}{l}\text { 1. Divergent thinking: } \\
(F(2.57)=4.015 ; p=0.023) \\
\text { 2. Overall creative potential: } \\
(F(2.57)=3.536 ; p=0.036) \\
\text { 3. Level of development of thinking: } \\
(F(2.57)=4.390 ; p=0.017) \\
\text { 4. Creativity in solving problems: } \\
(F(2.57)=3.855 ; p=0.027)\end{array}$ \\
\hline
\end{tabular}

Note: $\mathrm{F}$ is a value of Fisher criterion (F-criterion) - statistics of one-way analysis of variance (ANOVA). $p$ - the level of statistical significance of the results ( $p 0.05$ - high level of significance). 
uncreative group differs from the three different creative groups in terms of friendliness and altruism.

The generalised results of studying the influence of the effects of creativity on the indicators of personality adaptation in a politically and economically unstable environment are given in Table 10.

The results obtained within the study were interpreted according to the idea that the positive impact of creativity on the adaptability of an individual in a politically and economically unstable environment is indirect, through its manifestation in the processes of communication and adaptation. Creativity makes a person more efficient and flexible in interpersonal communication, increasing the degree of job satisfaction, and increases the ability to adapt to rapidly changing conditions in a politically and economically unstable environment, minimising psycho-emotional costs in stressful situations.

\section{DISCUSSION}

This study was an attempt to assess the impact of creativity on adaptation in a politically and economically unstable environment, taking into account the gender and age characteristics of respondents. The study found that there was an increase in all indicators of creativity, except for nonverbal creativity, whose growth was observed only in the period from 16-17 to 17-18 years because during this period there was a leap in the development of creativity. The maximum differences in all types of creativity were observed between 16-17-year-olds and 17-18-year-olds, which due to the peculiarities of this age period (17-18 years). Was characterised by maximum mobility of development, active restructuring of personality structure. It was also found that students with a high level of development of divergent thinking and its components (cognitive factors of creativity) carry out interpersonal communication (as a component of adaptation) most flexibly and effectively. The high level of development of divergent thinking makes students less prone to depersonalisation and reduces the risk of emotional exhaustion and maladaptation. Students with a high level of development of personal factors of creativity are more sensitive to changes in the situation, able to realise the novelty of the situation in a politically and economically unstable environment and formulate a pressing problem, as well as direct their activities to find all possible constructive ways to solve the problem, in particular, go beyond experience. Thus, in problematic and therefore, potentially or actual stressful situations, creative individuals implement constructive coping strategies, effectively coming out of stressful situations, rationally spending emotional resources, which significantly reduces the risk of maladaptation.

The results of the experiment relate to the objective of this study and correspond to the results of [25], which indicates that it is creative individuals who can quickly realise the need for change to apply active constructive strategies to solve problem situations. This is consistent with [26-28], which confirms that creative individuals achieve maximum results in the process of adaptation and therefore are aware of the importance of their personal contribution to solving problems. The findings of the study coincide with a study conducted by [29-31] to prove that the creative activity of an individual is a progressive adaptation mechanism and a special means of active adaptation when an individual lacks real experience. The study also expanded previous research on the formation of creativity within professional training [32] and the consideration of the adaptive function of creativity as an "anticipating" integration of reality [33].

The study provides a new understanding of creativity as a program of interaction with the environment, which provides optimal adaptation to various external influences. The basis of this program is a mechanism of anticipation, which includes emotional pre-configuration reactions and forecasting.

The results of the study can be challenged based on the number of students selected, the duration of the experiment, and the tools used to obtain statistics. Besides, the study did not assess the actual behaviour of respondents in a politically and economically unstable environment, but only the manifestations of individual factors of creativity and their relationship to the process of adaptation. Additionally, the dominant type of research, the limited set of measures used as a tool for engagement, can also be challenged and seen as a restriction.

\section{CONCLUSION}

The study found the relationship between to identify the development of creativity in student age and the peculiarities of socio-psychological adaptation, as well as gender and micro group patterns of the relationship between creativity and adaptability. There was found that the actualisation of nonverbal creativity, regardless of the level of its manifestation is associated with violations of personality adaptation, and at low rates of 
all creative types, the tendency characterises the verbal and nonverbal components of creativity. The parameters of motivational and personal creativity do not have a clear tendency to correlate with the adaptation by the parameters of a personality adaptive resource. The study revealed the relationship of manifestations of creativity with the problems of adaptation in the interpersonal sphere. The specifics of the manifestation of creativity by gender attribute is manifested as follows: in girls, indicators of creativity are associated mainly with the formation of personality adaptive resource, in boys - with interpersonal relationships. With age, creativity is increasingly involved in the system of interpersonal relationships.

The study theoretically and experimentally substantiated the possibility of considering creativity as a resource of adaptation in a politically and economically unstable environment. Empirical facts are obtained in favour of the fact that some factors of creativity have positive effects on the process of adaptation in a politically and economically unstable environment, raising its level. The results of the study became a prerequisite for the development of a specialised creativity training programme for students, aimed at developing their ability to actualise their creative potential in a politically and economically unstable environment. Based on the development of mental self-regulation skills and the use of constructive coping strategies.

Analysis of the results of the study suggests that the data obtained are only a particular case of manifestation of a deeper relationship between the creativity of an individual and the process of his adaptation in a politically and economically unstable environment. We consider further study of the problem to be validated and examined the hypothesis that creativity is an important factor in the adaptation and professional development of an individual in general. That determines its ability to realise and overcome adaptive barriers and find constructive solutions to life and professional crises.

Further study is needed in the mechanisms of the influence of creativity on the success of overcoming external and internal barriers to the adaptation of an individual in a politically and economically unstable environment, the results of which can be used to develop appropriate specialised technologies based on the application of creative activity stimulation techniques in the context of adaptation.

\section{ACKNOWLEDGEMENT}

We are thankful to all the participants from the higher and professional education institutions in Pereiaslav-Khmelnytskyi, and those who helped them and the research team to conduct the study and evaluate the results.

\section{REFERENCES}

[1] Kim KH, Pierce RA. Adaptive Creativity and Innovative Creativity. In EG Carayannis editor. Encyclopedia of Creativity, Invention, Innovation, and Entrepreneurship. New York: Springer 2013 https://doi.org/10.1007/978-1-4614-3858-8 21

[2] Goudie AS. Human impact on the natural environment. New Jersey: Wiley-Blackwell 2018

[3] Amabile TM. Componential Theory of Creativity. Harvard Business School Working Paper 2012; 12-096.

[4] Vasylkevych Y. Factors of Educational Influence on the Development of Creativity of Children. Latvijas Universitātesraksti sējums. Pedagoǵija un skolotājuizglīīība 2016; 811: 104-12.

[5] Oliver M, Shah B, McGoldrick C, Edwards M. Students experiences of creativity. Developing Creativity in Higher Education: An Imaginative Curriculum 2006; 15: 43-58.

[6] Ivanchenko A. Creative Life-Orientation in a Paradigm of Personality's Health and Positive Existence. Formazione \& Insegnamento: European Journal of Research on Education and Teaching 2013; XI (3): 43-58.

[7] Blessinger $P$, Sengupta E, Yamin TS. Human creativity as a renewable resource. International Journal for Talent Development and Creativity 2018; 6(1-2): 17-23.

[8] Zhou J, George JM. Awakening Employee Creativity: The Role of Leader Emotional Intelligence. Leadersh Q 2003; 14(4-5): 545-68.

https://doi.org/10.1016/S1048-9843(03)00051-1

[9] Schlesinger P, Doyle G. From organisational crisis to multiplatform salvation? Creative destruction and the recomposition of news media. Journalism (Lond) 2015 16(3): 305-23.

https://doi.org/10.1177/1464884914530223

[10] Watts L, Blessinger P. Creative learning in higher education: International perspectives and approaches. New York: Routledge Publishing 2016. https://doi.org/10.4324/9781315659473

[11] Brennan A, Dooley L. Networked creativity: a structured management framework for stimulating innovation. Technovation 2005; 25: 1388-99. https://doi.org/10.4324/9781315659473

[12] O'Connor GC, DeMartino R. Organizing for Radical Innovation: An Exploratory Study of the Structural Aspects of RI Management Systems in Large Established Firms. Journal of Production Innovation Management 2006; 23: 475-97. https://doi.org/10.1111/j.1540-5885.2006.00219.x

[13] Vasylkevych Y. Age dynamics of pupils' creativity. European humanities studies: state and society. Europejskie studia humanistyczne: Panstwo i Spoleczenstwo 2015; 3: 113-24.

[14] Vasylkevych Y. Modern tendencies of education of gifted youth. Europejskie studia humanistyczne: Panstwo i Spoleczenstwo 2016; 1: 129-39.

[15] Maggiori C, Rossier J, Savickas ML. Career Adapt-Abilities Scale -Short Form (CAAS-SF): Construction and Validation. J Career Assess 2015; 25(2): 312-25. https://doi.org/10.1177/1069072714565856 
[16] Baer M. Putting Creativity to Work: The implementation of creative ideas in organisations. Academy of Management Journal 2012; 55 (5): 1102-19. https://doi.org/10.5465/amj.2009.0470

[17] Farazmand A. Innovation in Strategic Human Resource Management: Building Capacity in the Age of Globalization. Public Organization Review 2004; 4(1): 3-24. https://doi.org/10.1023/B:PORJ.0000015649.54219.b7

[18] Fillis I, Rentschler R. The Role of Creativity in Entrepreneurship. Journal of Enterprising Culture 2010; 18(1): 49-81. https://doi.org/10.1142/S0218495810000501

[19] Kaliszczak L. Warunki stymulowania twórczości, innowacyjności i przedsiębiorczości - wyzwania wobec przywódców współczesnych przedsiębiorstw (Terms of Stimulation of Creativity, Innovation and Entrepreneurship Challenges Facing the Leaders of Modern Business). Management 2012; 16(1): 737-48.

[20] McWilliam E, Hearn G, Haseman B. Transdisciplinarity for creative futures: What barriers and opportunities? Innovations in Education and Teaching International 2018; 45(3): 247-53. https://doi.org/10.1080/14703290802176097

[21] Baard SK, Rench TA, Kozlowski SWJ. Performance adaptation: A theoretical integration and review. Journal of Management 2014; 40(1): 48-99.

https://doi.org/10.1177/0149206313488210

[22] Kashdan TB, Biswas-Diener R, King LA. Reconsidering happiness: The costs of distinguishing between hedonics and eudaimonia. J Posit Psychol 2008; 3(4): 219-233. https://doi.org/10.1080/17439760802303044

[23] Maggiori C, Johnston CS, Krings F, Massoudi K, Rossier J. The role of career adaptability and work conditions on general and professional well-being. J Vocat Behav 2013; 83: $437-49$.

https://doi.org/10.1016/j.jvb.2013.07.001

[24] Jundt DK, Shoss MK, Huang JL. Individual adaptive performance in organisations: A review. J Organ Behav 2015; 36(1): 53-71.

https://doi.org/10.1002/job.1955
[25] Savickas ML, Porfeli EJ. Career Adapt-Abilities Scale: Construction, reliability, and measurement equivalence across 13 countries. J Vocat Behav 2012; 80(3): 661-73. https://doi.org/10.1016/j.jvb.2012.01.011

[26] Klimczuk-Kochańska M. Importance of creativity of employees in the adaptation of food companies to innovative trends in the world. Human Resources Management and Ergonomics 2017; 1 (XI): 50-64.

[27] Ulatowska R. Innowacje i nowe technologie przemyslow kreatywnych. Perspektywy rozwoju rynku audiowizualnego w Malopolsce (Innovations and new technologies in The Creative Industries. Prospects for the Development of the Audiovisual Market in Maiopolska). Krakow: Fundacja Rozwoju Kina 2012.

[28] Dixon S, Meyer K, Day M. Building dynamic capabilities of adaptation and innovation: a study of micro-foundations in a transition economy. Long Range Plann 2014; 47(4): 186-205. https://doi.org/10.1016/j.Irp.2013.08.011

[29] Jaruzelski B, Staack V, Goehle B. The Global Innovation 1000: Proven Paths to Innovation Success. Strategy+Business [serial on the Internet]. 2014 Oct 28; [cited 2020 September 22]. Available from: https://www.strategybusiness.com/article/00295?gko=8a0a5

[30] Zhou M, Lin W. Adaptability and Life Satisfaction: The Moderating Role of Social Support. Front Psychol 2016; 7: 1134-45.

https://doi.org/10.3389/fpsyg.2016.01134

[31] Oliver JJ. Exploring industry level capabilities in the UK Creative Industries. Creative Industries Journal 2017; 10-11: 1105-21.

https://doi.org/0.1080/17510694.2017.1282302

[32] Blessinger $P$, Sengupta E, Yamin TS. Higher education for a sustainable future. University World News [serial on the Internet]. 2018 Nov 30;[cited 2020 September 22]. Available from: https://www.universityworldnews.com/post.php? story $=20181128082326995$

[33] Norton LW. Flexible leadership: An integrative perspective. Consulting Psychology Journal: Practice and Research 2010; 60(2): 143-50. https://doi.org/10.1037/a0019990

Received on 12-10-2020

Accepted on 17-11-2020

Published on 27-11-2020

DOI: https://doi.org/10.6000/2292-2598.2020.08.04.14

(C) 2020 Vasylkevych et al.; Licensee Lifescience Global.

This is an open access article licensed under the terms of the Creative Commons Attribution Non-Commercial License (http://creativecommons.org/licenses/by-nc/3.0/) which permits unrestricted, non-commercial use, distribution and reproduction in any medium, provided the work is properly cited. 